\title{
Construction Technology of Large Thickness Vibratory Compaction of Hard Rock Embankment
}

\author{
Aijun Chen, Chunhui Su*, Xianyuna Tang, Junhua Chen \\ School of Architecture and transportation Engineering, Guilin University of electronic technology, Guilin, Guangxi, 541004, China
}

\begin{abstract}
In order to provide technical guidance for the construction of rock embankment with a thickness greater than $60 \mathrm{~cm}$, the high-power roller with self-weight of 32t and supporting construction machinery have been used to carry out field experiments on vibration compaction of large thickness rock embankment, and several indexes of compaction quality have been compared and evaluated, so the quality detection method and evaluation criteria of large thickness vibration compaction of rock embankment have been obtained. The results shows that for the vibration compaction of the hard rock embankment with large thickness, the effective rolling thickness of the high-power vibratory roller with $32 \mathrm{t}$ weight is $90 \mathrm{~cm}$. It is suggested that the comprehensive parameters such as looseness coefficient, settlement difference and construction technology should be adopted to evaluating compaction quality. The standard of compacting quality is: the looseness coefficient should be greater than 1.16, the average settlement difference of the last rolling should not exceed 5mm, and the high-power roller should roll more than 6 times.
\end{abstract}

\section{Introduction}

The construction of Expressway in mountainous area will produce a lot of excavated stones. In order to reduce project cost, waste and environmental pollution, the excavated stones should be used as embankment filler as far as possible. The Code for Design of Highway Subgrade (JTG D30-2015) stipulates that the layer thickness of the upper and lower embankments of rockfill embankments shall be less than $40 \mathrm{~cm}$ and $60 \mathrm{~cm}$ respectively, and the compaction quality shall be controlled by porosity. It can be seen that the current code does not put forward the compaction quality standard for the construction of rockfill embankment with layer thickness more than $60 \mathrm{~cm}$.

However, with the continuous improvement of mechanical manufacturing technology, the application of high-power vibratory roller with a weight of more than $25 \mathrm{t}$ in highway, railway and hydraulic engineering is becoming more and more popular. High-power vibratory compaction can not only improve the density of embankment, reduce post-construction settlement and enhance the stability of subgrade, but also increase the thickness of filling layer to speed up the construction and reduce the construction cost. Therefore, the engineering companies very much hope to use high-power roller to compact the rock-filler with large thickness (more than $60 \mathrm{~cm}$ ). Because there is no corresponding stipulation in the current code, the following problems must be solved when adopting large thickness vibration compaction: first, what kind of construction machinery should be adopted and how to determine the effective layer thickness? Secondly, what compaction index is used to control compaction quality and how to determine its quality standard?

According to the research of construction methods of rock-filled embankment in recent years [1], the compaction methods of rock-filled embankment generally include impact roller compaction [2-5], dynamic compaction [6-7] and conventional vibration compaction [8], in which impact compaction and dynamic compaction are mainly used for supplementary compaction after vibration compaction [4][6]. For the vibration compaction of rock-filled embankments, it is common for construction companies to use ordinary heavy-duty vibratory roller [2-6] whose weight is between $15 \mathrm{t}$ and $20 \mathrm{t}$. In individual rock-filled embankments, 20-25t ultra-heavy vibratory roller [7-8] has been used. Due to the different compaction work produced by vibratory compactors with different weights, the corresponding effective layer thickness and detection methods of compaction quality are also different.

The above research shows that the suitable layer thickness is less than $50 \mathrm{~cm}$ for $18 \mathrm{t}$ vibratory roller, and that is in the range of $60 \mathrm{~cm}$ to $80 \mathrm{~cm}$ for $20 \mathrm{t}$ to $25 \mathrm{t}$ large-tonnage roller. The compaction quality index are not identical, and settlement difference (rate) are widely used because of its clear meaning of and simplicity and practicability.

In order to solve the problems encountered by high-power vibratory roller in the construction of large-thickness rock-filled embankment, a high-power vibratory roller (YZ32) with self-weight of $32 t$ and maximum exciting force of $590 \mathrm{kN}$, was used to carry out field tests. The compaction quality of embankment was

*Corresponding author's e-mail: sch3977@163.com 
evaluated by various compaction detection indexes, and the large thickness was determined by the analysis of compaction effect. Vibration compaction technology for hard rock embankment is carried out, and the detection methods of corresponding compaction quality and quality controlling standards are put forward.

\section{General Situation of Testing Road}

The testing section of rock-filled embankment is located on Zhijin-Nayong Expressway in Guizhou Province. The mileage pile number is CK $1+040$ to $\mathrm{CK} 1+090$, the width of the embankment is $10.5 \mathrm{~m}$, the height of the

Table. 1 Technical parameters of vibratory roller

\begin{tabular}{cccccccc}
\hline Roller Model & Self-weight $(\mathrm{t})$ & $\begin{array}{c}\text { Steel wheel load } \\
\mathrm{t})\end{array}$ & $\begin{array}{c}\text { Static line } \\
\text { pressure }(\mathrm{N} / \mathrm{cm})\end{array}$ & $\begin{array}{c}\text { Frequency } \\
(\mathrm{Hz})\end{array}$ & $\begin{array}{c}\text { Amplitude( } \\
\mathrm{mm})\end{array}$ & $\begin{array}{c}\text { Exciting } \\
\text { force }(\mathrm{kN})\end{array}$ & $\begin{array}{c}\text { Compaction } \\
\text { width }(\mathrm{mm})\end{array}$ \\
\hline YZ32 & 32 & 21 & 960 & $28 / 33$ & $1.8 / 1.1$ & $590 / 450$ & 2180 \\
CLG620 & 20 & 10 & 460 & $30 / 32$ & $2.0 / 1.0$ & $400 / 210$ & 2130 \\
\hline
\end{tabular}

\section{Compacting scheme of testing road}

According to the existing research results, the economic thickness of compacted layer is related to the type of soil and roller. In this project, the compacted layer thickness should be more than $60 \mathrm{~cm}$ when the high-power vibratory roller is used to compact the rock-filled embankment. Therefore, the layer thickness of rock-filled embankment is controlled in the range of $70-110 \mathrm{~cm}$. In the same test section, the virtual layer thickness of $70 \mathrm{~cm}, 90 \mathrm{~cm}, 100 \mathrm{~cm}$ and $110 \mathrm{~cm}$ is adopted from bottom to top. The maximum particle size of filler is $2 / 3$ of the thickness of the layer. Among them, the second layer is compacted by Liugong vibratory roller until no settlement occurs, then compacted by large-power vibratory roller to stabilize, while the other layer is compacted directly by large-power vibratory roller.

Rolling scheme of embankment includes selection of compacting machinery, running speed of roller, rolling times and overlapping width of vibration wheel tracks. Start with the high-power roller static rolling once and measure the top elevation, and virtual height equals top elevation to bottom elevation. Then the weak vibrating make the filler preliminary stabilization, followed by strong vibration rolling to compact and stable. Wheel tracks overlap by $1 / 3$ when static rolling and weak vibration, and $1 / 2$ when strong vibration rolling to avoid leakage area. The speed of roller is $2-4 \mathrm{~km} / \mathrm{h}$, and it can embankment center is 5-12m, the slope of the embankment slope is $1: 1.5$, and the embankment filler is limestone blasted in the excavation section nearby. The strength grade is strong rock. The gradation is not uniform, with more lumps with particle size over $6 \mathrm{~cm}$, the maximum particle size up to $60 \mathrm{~cm}$, and the content of fine material less.

In order to compare the compaction effect of high-power vibratory roller and common heavy-duty roller, a high-power roller (YZ32) and CLG620 roller are installed in the field. The technical parameters of the roller are shown in Table 1. be properly speeded up when static rolling. Because of the large thickness of the filling layer, the standard for stopping compaction is that the average value of the settlement difference is not more than $5 \mathrm{~mm}$.

\section{Evaluation of compaction quality of testing road}

In order to ensure the density, strength and stability of the rock-filled embankment, the author chooses several detecting indexes, such as settlement difference, rebound deflection and foundation coefficient $\mathrm{K}_{30}$, to evaluate the compaction quality of the rock-filled embankment from many aspects.

\subsection{Results analysis of rolling settlement}

In order to obtain the settlement of the testing road in the process of rolling, nine observation points of rolling settlement are evenly arranged on the testing embankment. The location of the observation points is measured by GPS positioning, and the elevation is measured by leveling. The elevation of observation points should be measured before and after each strong vibration, and the corresponding settlement difference should be calculated. Four layers of limestone filler were filled in the testing road. The corresponding settlement measurement data are shown in Table 2.

Table.2 Settlement measurement data of testing road

\begin{tabular}{ccccccccccc}
\hline $\begin{array}{c}\text { Filling } \\
\text { layer }\end{array}$ & 1 & 2 & 3 & 4 & 5 & 6 & $\begin{array}{c}\text { Average Settlement Difference/mm } \\
\text { Thickness } \\
\text { Thm }\end{array}$ & $\begin{array}{c}\text { Compaction } \\
\text { thickness } \\
/ \mathrm{mm}\end{array}$ & $\begin{array}{c}\text { Total } \\
\text { Settlement } \\
\text { Difference } \\
/ \mathrm{mm}\end{array}$ & $\begin{array}{c}\text { Looseness } \\
\text { coefficient }\end{array}$ \\
Layer 1 & 27 & 24 & 14 & 13 & 9 & 4 & 630 & 539 & 91 & 1.16 \\
Layer 2 & 63 & 20 & 16 & 12 & 8 & 4 & 861 & 738 & 123 & 1.17 \\
Layer 3 & 61 & 36 & 23 & 13 & 6 & 3 & 943 & 802 & 142 & 1.18 \\
Layer 4 & 42 & 29 & 18 & 13 & 8 & 5 & 1045 & 930 & 115 & 1.12 \\
\hline
\end{tabular}

From Table 2, it can be found that the virtual thickness of each layer is different from its planned thickness because of the lax construction management and the large size of fillers. In the second layer, Liugong roller is used to roll 6 times to stabilize, resulting in 63 
mm settlement difference; then, high-power roller is used to supplement compaction 5 times to stabilize again, and $60 \mathrm{~mm}$ settlement difference is produced, which shows that the supplementary compaction effect of high-power roller is obvious, and it is difficult to meet the requirement of compaction with large thickness by using conventional heavy roller. In addition, the average settlement difference of the other three-layer rolling for the sixth time is not more than $5 \mathrm{~mm}$, which shows that the filling layer can be stabilized after six times of high-power roller strong vibration rolling.

The relationship between compaction thickness and total settlement value of each layer and virtual thickness is analyzed, as shown in Fig. 1.

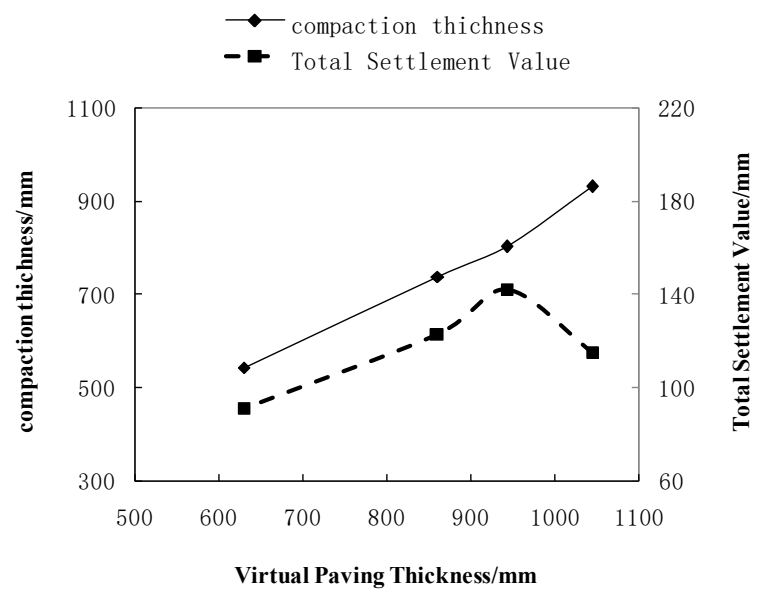

Fig. 1 the settlement variation of different virtual paving thickness

As can be seen from Fig. 1, the bigger the virtual thickness, the bigger the compaction thickness. In compaction process of the first three layers, the total settlement value increases with the increase of virtual thickness, while the total settlement value of the fourth layer does not increase. Meanwhile, the loosening coefficient of the first three layers are 1.16, 1.17 and 1.18 , respectively. The loosening coefficient of the three layers is very close (mean 1.17), while the loosening coefficient of the fourth layer is 1.12 , which is 0.05 lower than the average of the first three layers. The above analysis shows that the compactness of the first three layers after rolling is comparatively consistent, but the compactness of the fourth layer of packing after rolling stability is less than that of the first three layers. The reason is that the thickness of the fourth layer has exceeded the effective compaction thickness of the high-power roller, resulting in that the lower of layer can not meet the required density.

The relationship between the rolling times and the settlement difference of the four layers is shown in Fig. 2. The second layer is rolled by a common heavy roller for the first time.

Fig. 2 shows that the settlement difference of the four-layer decreases with the increase of rolling times, and does not exceed $5 \mathrm{~mm}$ at the sixth rolling time, which indicates that for hard-rock fillers with an average virtual thickness of $630 \mathrm{~mm}-1045 \mathrm{~mm}$, they can be stabilized after 6-7 times of vibratory compaction by high-power roller. However, this stable state does not mean that the filler density has reached the required density, but that the roller can not make the filler layer produce more obvious settlement. Literature [18] proposed that BMG vibratory roller with $25 \mathrm{t}$ self-weight (40 $\mathrm{t}$ exciting force) should roll 12 times to meet the requirement for hard-rock embankment with $80-100 \mathrm{~cm}$ looseness thickness. The weight and exciting force of YZ32 vibratory roller used in this paper are larger than those of BMG roller in reference [18], so the compaction efficiency is higher. The settlement requirement can be met by vibratory compaction 6 times.

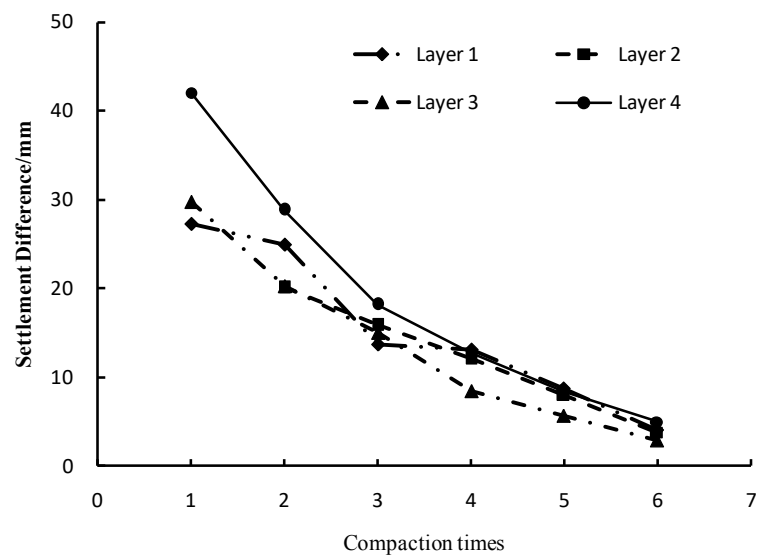

Fig.2 The Relation between Settlement Difference and Compaction times

In summary, considering the compaction effect and construction economy, the optimum rolling thickness of limestone filler with YZ32 roller is between $900 \mathrm{~mm}$ and $1000 \mathrm{~mm}$. It is suggested that the virtual thickness of 900 $\mathrm{mm}$ is more reasonable. The control standard of stopping rolling is that the average settlement difference is not more than $5 \mathrm{~mm}$.

\subsection{Testing results of rebound deflection}

In pavement design specifications, resilience modulus is generally used to characterize the bearing capacity of subgrade. Because the test of resilience modulus is complicated, the author uses $5.4 \mathrm{~m}$ Beckman beam to test the resilience deflection in the field, and then converts the resilience deflection into resilience modulus according to Specification for Design of Highway Asphalt Pavement (JTG D50-2017):

According to the requirements of pavement design specifications, the Resilience Modulus $\mathrm{E}_{0}=60 \mathrm{MPa}$ of subgrade which meets the requirements of pavement design is taken. The rebound deflection value is calculated to be $130(0.01 \mathrm{~mm})$, which serves as a reference standard for the strength of subgrade to meet the requirements. The deflection data of each layer are listed below, as shown in Table 3 . 
Table.3 Deflection results of each layer unit $/ 0.01 \mathrm{~mm}$

\begin{tabular}{cccccccccccc}
\hline $\begin{array}{c}\text { Detecting } \\
\text { point }\end{array}$ & 1 & 2 & 3 & 4 & 5 & 6 & 7 & 8 & 9 & 10 & $\begin{array}{c}\text { average } \\
\text { value }\end{array}$ \\
\hline Layer 1 & 20 & 12 & 48 & 28 & 20 & 34 & 32 & 22 & 16 & 22 & 25 \\
Layer 2 & 18 & 22 & 16 & 28 & 10 & 24 & 20 & 22 & 26 & 28 & 31 \\
Layer 3 & 20 & 30 & 8 & 16 & 42 & 38 & 16 & 48 & 24 & 22 & 26 \\
Layer 4 & 28 & 36 & 22 & 30 & 36 & 32 & 48 & 44 & 26 & 40 & 34 \\
\hline
\end{tabular}

Table 3 shows that the maximum deflection value is 48 and the minimum deflection value is 8 . The average values of layer 1, 2, 3 and 4 are 25, 31, 26 and 34, respectively, which are far less than the standard 130. It shows that after stabilizing the limestone filler with YZ32 roller, its deflection value can meet the requirements of the specification.

\subsection{Testing results of foundation coefficient}

Foundation coefficient $\mathrm{K}_{30}$ is a conventional index for controlling the compaction quality of railway subgrade. In this testing section, $K_{30}$ is used to evaluate the compaction quality of highway subgrade. The field testing data of $\mathrm{K}_{30}$ are shown in Table 4.

Table.4 Field testing data of $\mathrm{K}_{30}$

\begin{tabular}{|c|c|c|c|c|c|c|c|c|c|c|c|c|}
\hline Detecting Layer & & Layer 1 & & & Layer 2 & & & Layer 3 & & & Layer 4 & \\
\hline Pile Number & +050 & +070 & +080 & +050 & +070 & +080 & +050 & +070 & +080 & +050 & +070 & +080 \\
\hline $\mathrm{K}_{30}(\mathrm{MPa} / \mathrm{m})$ & 380 & 410 & 320 & 186 & 235 & 355 & 183 & 412 & 228 & 215 & 286 & 325 \\
\hline
\end{tabular}

In the process of $\mathrm{K}_{30}$ detection in this testing section, the $\mathrm{K}_{30}$ data measured at different locations vary greatly from $186 \mathrm{MPa} / \mathrm{m}$ to $412 \mathrm{MPa} / \mathrm{m}$; the $\mathrm{K}_{30}$ at better gradation can reach $300-400 \mathrm{MPa} / \mathrm{m}$, and the $\mathrm{K}_{30}$ at more fine particles and poorly gradation can range from $180-250 \mathrm{MPa} / \mathrm{m}$. The reason for the large variation of foundation coefficient is that the size of filler is larger and the gradation is very uneven. The poor gradation of filler is difficult to form a stable and dense structure, which leads to more holes and affects the $\mathrm{K}_{30}$ testing results. The size of filler is bigger, and it is far more than a quarter of the diameter of bearing plate, which also brings great errors to the testing results.

According to Technical Regulations for Subgrade of High Speed Railway (Q/CR9602-2015), K 30 should more than $130 \mathrm{MPa} / \mathrm{m}$ for gravel filler; $\mathrm{K} 30$ stipulated in Specification for Design of Railway Subgrade should be greater than $130 \mathrm{MPa} / \mathrm{m}$. Therefore, referring to the railway standard, even if there are various testing errors, the foundation coefficient $\mathrm{K}_{30}$ can still meet the subgrade compaction standard.

\section{5 conclusions}

(1) In view of the hard-rock embankment with layer thickness more than $60 \mathrm{~cm}$, it is not suitable to be compacted by vibratory roller with self-weight less than $20 \mathrm{t}$. High-power roller and supporting construction machinery can be used to compact the embankment, but the filling thickness and construction technology must be determined by the construction of the testing road.

(2) It is reasonable and feasible to use YZ32 roller to compact rock-filled embankment routinely. The maximum filling thickness is determined by the variation of settlement difference and looseness coefficient. The effective rolling thickness of hard filler is $90-100 \mathrm{~cm}$, and the thickness is recommended to be $90 \mathrm{~cm}$. The rolling parameters can be static rolling once, weak vibration once, strong vibration 6-7 times, driving speed $2-4 \mathrm{~km} / \mathrm{h}$, rolling wheel tracks overlap by one half.

(3) For hard-rock embankment, because of the large size and high strength of filler, the foundation coefficient are not suitable for evaluating compaction quality. Rebound deflection, as a mechanical index to characterize the overall strength and stiffness of subgrade, is closely related to the types of fillers. It is not recommended to be used as an evaluation index of subgrade compaction quality.

(4) It is suggested that the compaction quality of hard-rock embankment with large thickness should be evaluated comprehensively by the parameters of looseness coefficient, settlement difference and construction technology. The compaction quality standard of hard-rock embankment is that the looseness coefficient should be greater than 1.16, the average settlement difference of the last rolling should not exceed $5 \mathrm{~mm}$, and the strong vibration rolling of high-power roller should be more than 6 times.

\section{Reference}

1. Yang, M. H., Liu, G. X., Zhao, M. H. (2009) Vibration compaction characteristics of rock filling embankment. Journal of Central South University, 16: 1034-1038.

2. Yang, S.J., He Z.H., Wu L.J. (1999) Improvement on Compaction Techniques of Highway Stone Fill Embankment. Journal of Highway and Transportation Research and Development, 4:1-4.

3. Chen, P. (2004) Ideal method in rolling stone 
roadbed. Road Machinery \& Construction Mechanization, 11:44-46.

4. Lu, D., Deng, J.X., He, C.Z. (2005) Application of impaction roller to compaction the rockfill subgrade. Carsologica Sinica, 2:152-155.

5. Zhou, Y., Wu, L.J., Liu, S.C. (2010) Study on rolling compaction test of high rockfill subgrade of new expressway. Highway, 2:71-74.

6. Zhang, T.F., Wang, J.T., Wang, X.C. (2008) Test research on dynamic compaction at high filling sloping area of expressway. Rock and Soil Mechanics, 10:2775-2778.

7. Yang, J.H., Hu, Z.N. (2008) In-situ Experiment Study of Crushed Red-stone Embankment Intensified by Dynamic Compaction. Journal of Wuhan University of Technology, 3:90-94.

8. Zhang, W., Zhang, J.Z. (1999) Quality Control of Rockfill Subgrade Construction. Railway engineering, 9:30-31. 